\title{
Comparison of diagnostic accuracy of hysteroscopy and ultrasonography in relation to histopathology in cases of postmenopausal bleeding
}

\author{
Dilpreet K. Pandher ${ }^{1 *}$, Alka Sehgal ${ }^{1}$, Ranjeev Bhagat ${ }^{2}$, Poonam Goel ${ }^{1}$
}

\begin{abstract}
${ }^{1}$ Department of Obstetrics and Gynecology, ${ }^{2}$ Department of Pathology, Government Medical College and Hospital, Chandigarh, Punjab, India
\end{abstract}

Received: 17 September 2020

Revised: 31 October 2020

Accepted: 02 November 2020

\author{
*Correspondence: \\ Dr. Dilpreet K. Pandher, \\ E-mail: dr_dilpreet@yahoo.com
}

Copyright: () the author(s), publisher and licensee Medip Academy. This is an open-access article distributed under the terms of the Creative Commons Attribution Non-Commercial License, which permits unrestricted non-commercial use, distribution, and reproduction in any medium, provided the original work is properly cited.

\section{ABSTRACT}

Background: To evaluate the role of hysteroscopy and ultrasound in relation to histological findings in patients of postmenopausal bleeding and to find out the sensitivity, specificity, positive predictive, negative predictive values and accuracy of ultrasound and hysteroscopy.

Methods: A retrospective analysis of the 30 women who underwent hysteroscopic evaluation out of total 103 patients of postmenopausal bleeding over the period of one year (August 2017 and July 2018) was done. Records were taken out to collect the relevant information. USG and hysteroscopic findings were correlated with histopathology for the comparative analysis.

Results: Indications of hysteroscopy cases were suspected polyp (5), fractional curettage (F/C) technically not feasible (7), inconclusive USG reports (5), recurrent bleeding with normal fractional curettage report (4), no tissue on F/C (1), removal of intra-uterine contraceptive device (1). Causes of postmenopausal uterine bleeding were found to be atrophic endometrium including one case of senile cystic atrophy (33.3\%), secretory endometrium and endometrial polyps $(23.3 \%$ each) and endometrial malignancy $(20.0 \%)$ cases. Overall sensitivity, specificity, positive predictive value, negative predictive value and accuracy values of USG in various endometrial conditions was found to be $57.1 \%, 85.2 \%, 55.1 \%, 86.2 \%$ and $78.5 \%$ respectively and for hysteroscopy was $87.1 \%, 97.5 \%, 90.0 \%, 96.7 \%$ and $95.3 \%$ respectively.

Conclusions: Hysteroscopy is a minimally invasive, safe and effective modality with least complications and morbidity rate and an ideal method for establishing the pathology as well as offering therapeutic intervention simultaneously.

Keywords: Endometrial neoplasms, Hysteroscopy, Post menopause, Ultrasonography

\section{INTRODUCTION}

Postmenopausal bleeding (PMB) is one of the common presentations in the gynae OPD. The significance of the same with malignancies of reproductive organs is well established. ${ }^{1}$ Apart from clinical examinations and Pap smear, ultrasound is one of the commonest non-invasive modalities usually planned before any invasive procedures like aspiration cytology/fractional curettage. ${ }^{2}$
Hysteroscopy though ideal, use is limited because of either non-availability or being performed as minor surgical procedure in operation theatre even in the teaching tertiary care institutes like ours. This study was planned to evaluate the role of ultrasonography (USG) and hysteroscopy for determining the cause of PMB and to calculate sensitivity, specificity and positive predictive value (PPV), negative predictive value (NPV) and accuracy of these two modalities in relation to the 
diagnosis confirmed by histopathology reporting (HPR) in patients of postmenopausal bleeding.

\section{METHODS}

A retrospective analysis of all women who underwent hysteroscopic evaluation for postmenopausal bleeding (PMB) and needful intervention over the period of one year (August 2017 and July 2018) in the gynaecology department of Government medical college and hospital, Chandigarh was done. In this period, total 103 patients presented with post-menopausal bleeding due to the uterine cause. After ruling out obviously visible local or any medical cause, patients having global thickening of endometrium endometrium along with history and clinical findings also suggestive of endometrial malignancy, 73 women were subjected to fractional curettage. 30 women out of total cases required hysteroscopic evaluation and intervention according to the findings. The group of these 30 patients was included in the study for the retrospective analysis.

For every patient who underwent hysteroscopy for the PMB, available records were reviewed to collect data related to the indication for the need of hysteroscopy, for the detailed history regarding chief complaint and associated symptoms, time interval since menopause, amount and duration of bleeding, any drug intake, presence of any co-morbid conditions followed by menstrual and obstetric history, personal and family history particularly of any malignancy. Thorough medical and physical examination, per abdomen examination followed by gynaecological examination including per speculum examination, pap smear report, bimanual per vaginum examination and per rectal examination were noted.

Ultrasonography both trans abdominal and trans vaginal were noted to collect the information about uterine size, any lesion, endometrial thickness and adnexa. Ultrasound findings as per the endometrial thickness were divided as thin (up to $5 \mathrm{~mm}$ ), hyper plastic $(5-8 \mathrm{~mm})$, thick (9-30 $\mathrm{mm}$ ) and suggestive of polyp (focal lesions).

Findings of hysteroscopic view of endometrium were noted and divided into atrophic (thin and pale looking), normal (pink and fluffy), benign endometrial polyp (smooth, focal polypoidal lesion), intrauterine synechiae (fibrotic bands in the cavity) and suggestive of endometrial malignancy (irregular, friable, unhealthy looking endometrial growth with abnormal/ excessive vascularity). The histopathology reports were taken out to note the final diagnosis.

Diagnosis based on USG and hysteroscopic findings were correlated with the final histopathology reports. Eventually we analysed the data to find out the sensitivity, specificity and predictive values of these modalities.

\section{Statistical analysis}

Categorical variables were reported as counts and percentages. Group comparisons were made with the ChiSq test. Normality of quantitative data were checked by measures of kolmogorov Smirnov tests of normality. Continuous data were given as mean $\pm \mathrm{SD}$ and range or median and interquartile range, as appropriate for nonnormally distributed (skewed) data comparison based on the basis made by mann-whitney test. For normally distributed data, student t-test was applied to compare 2 groups. McNemar's test were used to see differences between two modalities. Sensitivity, specificity, positive predictive value and negative predictive value were calculated for endometrial thickness on ultrasonography and appearance on hysteroscopy, eventually compared with histopathology report.

\section{RESULTS}

Total 103 patients presented with PMB due to uterine cause in the study period, out of those 30 patients underwent hysteroscopic evaluation. Various indications for selecting these patients for hysteroscopy were focal endometrial lesion suggested of polyp in $40.0 \%$ cases followed by technically not amenable to fractional curettage $(23.3 \%)$, inconclusive ultrasound reports (16.6\%), recurrent bleeding episodes in spite of previous normal histopathology on fractional curettage specimen (13.3\%), no tissue obtained on $\mathrm{f} / \mathrm{c}$ and removal of forgotten impacted intra-uterine contraceptive device (3.3\% each).

\section{Age distribution}

Maximum number of patients presenting with PMB in our study was in 51- 55 years age group (36.6\%) but the incidence of malignancy was observed to be more with the advancing age.

\section{Age since menopause}

The bleeding complaint in relation to the interval since menopause varied from delayed menopause to more than 20 years, maximum number $(36.6 \%)$ was seen within 5 years of menopause.

\section{Duration of bleeding}

It's heartening to know the awareness level of patients of our region since many of them reported within few days, almost half of total cases $(46.6 \%)$ presented within a month.

\section{Co morbidities}

Commonest co morbidity was hypertension (59.9\%) followed by diabetes $(20.0 \%)$, hypothyroidism $(16.6 \%)$, obesity $(6.6 \%)$. Significantly, the history of malignancies 
in self or family was forth coming in $4(13.2 \%)$ out of total 6 cases of endometrial malignancy.

On ultrasonography, endometrium was suggestive of polyp (focal lesions) in maximum number of cases (40\%), found to be thin in $20 \%$ cases (half of these had cavity opened up with collection inside), hyper plastic $(20 \%)$, thick $(16.7 \%)$ and inconclusive in $3.3 \%$ cases.

On hysteroscopic view, the endometrial cavity showed polyp in $26.6 \%$ cases, found to be atrophic in $23.3 \%$ and another $10 \%$ had thin endometrium but collection inside endometrial cavity, suspicious of endometrial cancer in $20 \%$, normal in $10 \%$, hyperplastic in $6.6 \%$ and intrauterine synechiae in $3.3 \%$ cases.

Histology reports of the tissue obtained during hysteroscopy of the cases of postmenopausal bleeding varied from benign conditions to frank malignancies. Most common cause of PMB was found to be atrophic endometrium $(33.3 \%)$ include one case of senile cystic atrophy, followed by secretory endometrium and endometrial polyps with similar incidence (23.3\%). Adenocarcinoma endometrium was found to be the least common cause of PMB $(20.0 \%)$ in present study. Malignancy cases which needed hysteroscopic guided biopsies were limited to the early stages only.

Comparative breakdown of ultrasonographic findings and histological reports obtained is shown in (Table 1). In 6 cases of ultrasonographically thin endometrium, 5 were actually reported to be inadequate or descriptive endometrium but 1 case had HP report of secretory endometrium. In 6 cases of hyperplastic endometrium, HPR was secretory in 3 cases whereas 2 were reported as inadequate curettings and 1 as endometrial polyp.

Table 1: Correlation between USG and HPE.

\begin{tabular}{|llllll|}
\hline ET (endometrial thickness) on ultrasonography & & & Histopathology report \\
\hline$<\mathbf{5 m}$ (Thin) & $\mathbf{5 - 8} \mathbf{~ m m}$ (Hyperplastic) & Polyp & $\mathbf{9 - 3 0 ~} \mathbf{~ m}$ (Thick) & Total & \\
\hline $\mathbf{5}$ & 2 & 2 & 0 & 9 & Inadequate/descriptive \\
\hline $\mathbf{1}$ & 3 & 2 & 1 & 7 & Secretory \\
\hline- & 1 & 5 & 1 & 7 & Polyp \\
\hline- & - & 1 & - & 1 & S cystic atrophy \\
\hline- & - & 2 & 3 & 5 & Adenocarcinoma \\
\hline $\mathbf{6 ( 2 0 . 7 \% )}$ & $6(20.7 \%)$ & $12(41.4 \%)$ & $5(17.2 \%)$ & 29 & Total \\
\hline
\end{tabular}

In one case, USG was not possible due to post surgery and radiotherapy vaginal stenosis and abdominal scarring hence technical limitations of USG.

Table 2: Correlation between hysteroscopy and HPE.

\begin{tabular}{|llllll|l|}
\hline Hysteroscopy & & & & Suspicion of malignancy & Total & Histopathology \\
\hline Thin/atrophied & Normal & Polyp & I/Ut bands & Sutedescriptive \\
\hline $\mathbf{8}$ & - & 1 & - & - & 9 & Inadequate/dent \\
\hline- & - & - & 1 & - & 1 & Senile cystic atrophy \\
\hline $\mathbf{2}$ & 5 & - & - & 0 & 7 & Secretory \\
\hline- & - & 7 & - & - & 7 & Polyp \\
\hline- & - & - & - & 6 & 6 & Adenocarcinoma \\
\hline $\mathbf{1 0}(\mathbf{3 3 . 3 \%})$ & $5(16.6 \%)$ & $8(26.7 \%)$ & $1(3.3 \%)$ & $6(20.0 \%)$ & 30 & Total \\
\hline
\end{tabular}

Table 3: Correlation of ultrasonographic, hysteroscopic, histological findings.

\begin{tabular}{|lllllllllll|}
\hline \multirow{2}{*}{ Histopathology } & Sensitivity \% & Specificity \% & PPV \% & \multicolumn{2}{c|}{ NPV \% } & \multicolumn{2}{c|}{ Accuracy \% } \\
\hline Thin/ descriptive & USG & Hyster & USG & Hyster & USG & Hyster & USG & Hyster & USG & Hyster \\
\hline Borderline/secretory & 55.5 & 88.9 & 95.0 & 90.5 & 83.3 & 80.0 & 82.6 & 95.0 & 82.8 & 90.0 \\
\hline Polyp & 42.9 & 71.4 & 86.4 & 100 & 50.0 & 100 & 82.6 & 92.0 & 75.9 & 93.3 \\
\hline Thickened/malignancy & 60.0 & 100 & 87.5 & 100 & 50.0 & 100 & 91.3 & 100 & 82.7 & 100 \\
\hline Overall & 57.1 & 87.1 & 85.2 & 97.5 & 55.1 & 90.0 & 86.2 & 96.7 & 78.5 & 95.3 \\
\hline
\end{tabular}

In 12 cases of USG diagnosed as endometrial polyp, only 5 were confirmed to be the same on histopathology, 2 each were reported as secretory endometrium, and adenocarcinoma endometrium. 2 cases were reported as descriptive tissue out of which one had actually very thin endometrium on hysteroscopy in which we think the 
reason could be a polyp that could have been expelled in the preoperative time since our institute protocol is to insert $200 \mathrm{mg}$ misoprostol pervaginum 3 hours prior to the procedure. This minimizes chances of failure of the hysteroscopy procedure which was nil in our study. One of these cases of suspected polyps on USG due to multiple focally thickened areas showed intrauterine bands on hysteroscopy and was reported as senile cystic atrophy on histopathology.

Total 5 cases of thickened endometrium with indistinct endomyometrial junction suspected to be endometrial malignancy, 3 were confirmed as adenocarcinoma endometrium and 1 case was diagnosed to be of polyp and secretory endometrium each. In cases of USG thin endometrium and hyperplastic endometrium, no case was carrying endometrial malignancy so thin endometrium on USG has good specificity in ruling out endometrial malignancy.

Comparative breakdown of hysteroscopic findings and histological reports obtained in postmenopausal bleeding cases is shown in (Table 2). Hysteroscopic findings were very much close to the final HPR. In 10 cases of thin looking endometrium, HPR turned out to be inadequate or descriptive in 8 cases, secretory in 2 cases. There were 5 cases of normal looking endometrium, all of which were reported to be secretory on histopathology. No case of endometrial malignancy was there in these 15 cases.

In 8 cases of smooth benign looking polyps on hysteroscopy, HPR was confirmed to be the same in 7 cases but in 1 case, removed specimen was reported to be inadequate on histopathology. One case of hysteroscopic findings of intrauterine bands was found to due to senile cystic atrophy on histopathology. Endometrium was suspicious of malignancy in 6 cases and it was proven to be the same in all these cases. The correlation between hysteroscopy and histology was found to be good in our study.

Eventually, we compare our suspicions based on ultrasound \& hysteroscopy findings with the histopathological reports to calculate Sensitivity, specificity, positive predictive value and negative predictive value (\%) for ultrasonography and hysteroscopy as shown in (Table 3).

Sensitivity of USG in diagnosing thin endometrium, where HPR was also found to be atrophic or descriptive was only $55.5 \%$ but specificity was as high as $95.0 \%$. PPV and NPV for endometrium found to be thin on USG was $83.3 \%$ and $82.6 \%$ respectively.

For USG hyperplastic endometrium with histopathology result of secretory phase, sensitivity and specificity of USG was $42.9 \%$ and $86.4 \%$ respectively with PPV and NPV of $50.0 \%$ and $82.6 \%$ respectively. Sensitivity, specificity, PPV and NPV of USG in diagnosing polyp was $71.4 \%, 68.2 \%, 41.7 \%$ and $88.2 \%$ respectively. USG suspicion of endometrial malignancy had sensitivity, specificity, PPV and NPV values were $60.0 \%$, 87.5\%, $50 \%$ and $91.3 \%$ respectively. Overall sensitivity, specificity, PPV, NPV and accuracy values of USG in various endometrial conditions was found to be $57.1 \%$, $85.2 \%, 55.1 \%, 86.2 \%$ and $78.5 \%$ respectively.

According to our study, on comparing hysteroscopic findings and histopathological results, hysteroscopic findings of normal thin endometrium showed a sensitivity of $88.9 \%$, specificity of $90.5 \%$ whereas sensitivity of hysteroscopy in cases of normal looking pink endometrium was $71.4 \%$, specificity was $100 \%$. PPV and NPV for diagnosing normal endometrium were found to be $100 \%$ and $92.0 \%$ respectively. The sensitivity, specificity, PPV, and NPV for diagnosis of polyp on hysteroscopy were $100 \%, 95.6 \%, 87.5 \%$ and $100 \%$ respectively. For detection of endometrial malignancy, the sensitivity, specificity, PPV, and NPV of hysteroscopy were all 100\%. Overall sensitivity, specificity, PPV, NPV and accuracy values of hysteroscopy in various endometrial conditions was found to be $87.1 \%, 97.5 \%, 90.0 \%, 96.7 \%$ and $95.3 \%$ respectively.

\section{DISCUSSION}

We divided the USG measured endometrial thickness as thin if less than $5 \mathrm{~mm}$, hyperplastic if between 5 to $8 \mathrm{~mm}$ and thick if more than $8 \mathrm{~mm}$ as described in literature. Endometrium is said to be hyperplastic if endometrial thickness on USG measures $>5 \mathrm{~mm}$ in a postmenopausal women not on HRT. ${ }^{3}$ SRU consensus recommends using an endometrial thickness measurement cut off as $5 \mathrm{~mm}$ or less. ${ }^{4}$ That has sensitivity of $96 \%$ contrary to ACOG committee opinion which advice cut off endometrial threshold of $4 \mathrm{~mm}$ or less which has almost same sensitivity but the specificity reduces with high false positive rate. $^{5}$

In the present study of 30 cases of postmenopausal bleeding who underwent hysteroscopy, most common cause of postmenopausal bleeding was detected to be inadequate or descriptive tissue in 9 (30.0\%) cases, secretory endometrium and polyps were the second common diagnosis in $7(23.3 \%)$ cases each, followed by malignancy in $6(20.0 \%)$ cases. There was $1(3.3 \%)$ case of senile cystic atrophy.

A study by Tandulwadkar et al has reported incidence of normal endometrium $(66.6 \%)$ to be the highest in the cases of PMB. $^{6}$ Our study also found normal endometrium that includes inadequate, descriptive and secretory constitutes $53.3 \%$ cases of PMB. Incidence of endometrial malignancy was found to be $20.0 \%$ in our study. Various authors have reported comparatively lower incidence of malignancy in the range of $8-12 \%$. However, one study reported incidence of endometrial cancer to be $28 \%$ as a cause of PMB which was high as compared to our study. ${ }^{6-8}$ 
In our study, polyp was most common pathology detected on USG $(40.0 \%)$ but found to be the second common cause of PMB on hysteroscopy (26.6\%) and histopathology $(23.3 \%)$. A study by Sonja et al reported endometrial polyp as the most common finding in PMB cases on hysteroscopy $(29.6 \%)$ whereas in our study endometrium was visualized to be thin in maximum proportion $(43.3 \%)$ of cases. ${ }^{9}$

Endometrial hyperplasia is the cause of PMB in $4-8 \%$ cases. $^{3}$ In the present study, we found hyperplastic endometrium on USG in 6 cases $(20.7 \%)$, hysteroscopic view could appreciate the fluffiness of endometrium in only 3 cases $(10.3 \%)$. Curettings obtained were adequate in these 3 cases and histopathology report was secretory making the sensitivity and NPV of USG for this condition to be $42.9 \%$ and $82.6 \%$ respectively.

In our study, the uterine cavity was suspected to have pathology in $90.0 \%(26 / 29)$ on USG which was comparable to the incidence quoted in literature. ${ }^{10}$ Which was brought down to $56.7 \%$ (17/30) on doing hysteroscopy, and was proven in $46.7 \%$ (14/30) by histology. The results of other studies indicate comparatively high percentage of abnormal hysteroscopic findings in PMB cases (69\% by Sunitha et al and $80 \%$ by Lasmar et al). Better accuracy of hysteroscopy justifies its use in cases of postmenopausal bleeding. ${ }^{11,12}$

Tinelli detected 3 cases of endometrial malignancy even if endometrial thickness was $<4 \mathrm{~mm}$ hence diagnostic accuracy of $87 \% .{ }^{13}$ Hysteroscopy revealed diagnostic accuracy of $94 \%$. In our study, endometrial malignancy was not seen in any case of sonographic endometrium thickness $<5 \mathrm{~mm}$ and atrophic looking endometrium on hysteroscopy proving the diagnostic accuracy to be $100 \%$.

Diagnostic accuracy of TVS for synechiae is not evaluable. ${ }^{14}$ Sonohysterography shows high PPV (100\%) and NPV (100\%) for synechiae assessment. In our study, one case had multiple focal areas of thickening with increased echogenicity on USG which on hysteroscopic visualization turned out to have intrauterine synechial bands and histopathology report was of senile cystic atrophy. Hence, we also conclude that USG is inconclusive for diagnosis of intrauterine synechiae. Hysteroscopy helps in diagnosis of this condition.

In our study, there were 3 cases of abnormal hysteroscopic findings that were proved to be normal on histology, 1 case was of hyperplastic endometrium with fleshy and plenty of curettings, 1 case of focal red suspicious area and 1 was a polyp. On the other side, there was no case of intrauterine pathology which was missed by hysteroscopy and later appeared on histology so hysteroscopy has high sensitivity and NPV of $100 \%$ for polyp and unhealthy-looking thickened endometrium. Same observation has been reported by a study which reports that it is difficult to miss polyps and endometrial cancer hysteroscopically and in combination with biopsy the possibility of error is $0 \% .^{8}$

In a study by Yela et al ultrasonography had a sensitivity of $95.6 \%$, a specificity of $7.4 \%$, a positive predictive value of $53.3 \%$ and a negative predictive value of $60 \%$, while the hysteroscopy had sensitivity, specificity, PPV and NPV of $95.7 \%, 83 \%, 82.2 \%$ and $95.9 \%$ respectively. ${ }^{15}$ As compared to this study, we found USG to have low sensitivity of $57.1 \%$ in picking up various pathologies but much better specificity of $85.2 \%$, PPV was almost the same $(55.1 \%)$ and a better NPV of $86.2 \%$. Similarly, in our study hysteroscopy was found to be a better modality than USG with sensitivity, specificity, PPV and NPV of $87.1 \%, 97.5 \%, 90.0 \%$ and $96.7 \%$ respectively. Overall accuracy of USG and hysteroscopy was found to be $78.5 \%$ and $95.3 \%$ in our study.

The reporting and outcome of hysteroscopy can be improved by keeping the fluid pressure low during this procedure just to ensure optimal visualization, it will also help in reducing other complications like fluid overload, pain during office hysteroscopy, missing out submucosal fibroids which may get compressed under high pressures. ${ }^{16,17}$

\section{CONCLUSION}

Hysteroscopy though minimally invasive, safe and effective modality with least complications and morbidity rate appears to be underutilized but an ideal method for establishing the pathology as well as offering therapeutic intervention simultaneously. Correlated ultrasound findings can vary with skill, experience and quality of resonance of machine and hence correlating your findings of different modalities are likely to improve interpretations.

\section{Funding: No funding sources Conflict of interest: None declared \\ Ethical approval: Not required}

\section{REFERENCES}

1. Hacker NF, Moore JG. Essentials of obstetrics and gynecology, 3rd ed. Philadelphia: WB Saunders, 1998:635.

2. Munro MG. Investigation of Women with Postmenopausal Uterine Bleeding: Clinical Practice Recommendations. Perm J. 2014;18(1):55-70.

3. Rezvani M, Winter TC. Abnormal Uterine Bleeding: The Role of Ultrasound. Norton M E, Scoutt L M, Feldstein V A, editors. Callen's Ultrasonography in Obstetrics and Gynecology. Elsevier. 2016:6e:83545.

4. Doubilet PM. Society of Radiologists in Ultrasound Consensus Conference statement on postmenopausal bleeding. J Ultrasound Med. 2001;20(10):1037-42.

5. American College of Obstetricians and Gynecologists. ACOG Committee Opinion No. 734: 
The role of transvaginal ultrasonography in evaluating the endometrium of women with postmenopausal bleeding. Obstet Gynecol. 2018; 131(5):e124-9.

6. Tandulwadkar S, Deshmukh P, Lodha P, Agarwal B. Hysteroscopy in postmenopausal bleeding. J Gynecol Endosc Surg. 2009;1(2):89-93.

7. Munawar S, Kamal F, Munawar F. Morphological pattern of endometrial lesions in postmenopausal bleeding. Biomedica. 2018;34(1):10-4.

8. Yusuf S, Shaheen M, Rana T. Frequency of endometrial carcinoma in patients with postmenopausal bleeding. Ann Kin Edw Medic Univ. 2010;16(4):290-4.

9. Trajkovi-Dinic S P, Ljubic A, Kopitovic V, Antic V, Stamenovic S, Pjevic AT. The role of hysteroscopy in diagnosis and treatment of postmenopausal bleeding. Vojnosanit Pregl. 2013;70(8):747-50.

10. Shokouhi B. Role of transvaginal ultrasonography in diagnosing endometrial hyperplasia in pre- and postmenopause women. Niger Med. 2015;5566:353-6.

11. Sunitha $\mathrm{CH}$. A clinical study of diagnostic hysteroscopy in abnormal uterine bleeding and its histopathological correlation (Doctoral dissertation, RGUHS).

12. Lasmar RB, Dias R, Barrozo PR, Oliveira MA, Coutinho E da S, da Rosa DB. Prevalence of hysteroscopic findings and histologic diagnoses in patients with abnormal uterine bleeding. Fertil Steril. 2008;89(6):1803-7.

13. Tinelli R, Tinelli FG, Cicinelli E, Malvasi A, Tinelli A. The role of hysteroscopy with eye-directed biopsy in postmenopausal women with uterine bleeding and endometrial atrophy. Menopause. 2008;15(4):73742.

14. La Sala G B, Blasi I, Gallinelli A, Debbi C, Lopopolo G, Vinci V, Villani M T, Iannotti F. Diagnostic accuracy of sonohysterography and transvaginal sonography as compared with hysteroscopy and endometrial biopsy: a Prospective Study. Minerva Ginecol. 2011;63(5):421-7.

15. Yela DA, Ravacci SH, Monteiro IM, Pereira KC, Gabiatti JR. Comparative study of transvaginal ultrasound and outpatient hysteroscopy for diagnosing pathologic endometrial lesions in postmenopausal women. Rev Assoc Med Bras. 2009; 55(5):553-6.

16. Deffieux X, Gauthier T, Menager N, Legendre G, Agostini A, Pierre F. Prevention of the Complications Related to Hysteroscopy: Guidelines for Clinical Practice. J Gynecol Obstet Biol Reprod. 2013;42(8):1032-49.

17. Karaman E, Kolusarı A, Çetin O, Çim N, Alkış İ, Karaman Y, et al. What should the optimal intrauterine pressure be during outpatient diagnostic hysteroscopy? A randomized comparative study. J Obstet Gynaecol Res. 2017;43(5):902-8.

Cite this article as: Pandher DK, Sehgal A, Bhagat R, Goel P. Comparison of diagnostic accuracy of hysteroscopy and ultrasonography in relation to histopathology in cases of postmenopausal bleeding. Int J Reprod Contracept Obstet Gynecol 2020;9:4995-5000. 